America, which retain several rather generalised mammalian characters, and are related to some of the earliest known European Miocene forms, are both to the present day exclusively fluviatile, being found in the rivers they inhabit almost up to their very sources, more than a thousand miles from the sea. May this not point to the freshwater origin of the whole group, and thus account for their otherwise inexplicable absence from the Cretaceous seas?

We may conclude by picturing to ourselves some primitive generalised, marsh-haunting animals with scanty covering of hair like the modern hippopotamus, but with broad, swimming tails and short limbs, omnivorous in their mode of feeding, probably combining water plants with mussels, worms, and freshwater crustaceans, gradually becoming more and more adapted to fill the void place ready for them on the aquatic side of the borderland on which they dwelt, and so by degrees being modified into dolphin-like creatures inhabiting lakes and rivers, and ultimately finding their way into the ocean. Here the disappearance of the huge Enaliosaurians, the Ichthyosauri and Plesiosauri, which formerly played the part the Cetacea do now, had left them ample scope. Favoured by various conditions of temperature and climate, wealth of food supply, almost complete immunity from deadly enemies, andillimitable expanses in which to roam, they have undergone the various modifications to which the Cetacean type has now arrived, and gradually attained that colossal magnitude which we have seen was not always an attribute of the animals of this group.

Please to recollect, however, that this is a mere speculation, which may or may not be confirmed by subsequent palæontological discovery. Such speculations are, I trust, not without their use and interest, especially when it is distinctly understood that they are offered only as speculations and not as demonstrated facts.

\section{THE AMERICAN OBSERVATIONS OF THE ECLIPSE}

NEWS of the American observations of the last eclipse has now arrived, and although details are yet wanting, enough information has been sent to show us that, as was to be expected, the American observers have left their mark upon the work. The telegram given below has been forwarded to me by the editors of Science, and is one transmitted by Prof. Holden to Prof. Young on the arrival of the former at San Francisco :-

\section{"San Francisco, Cal., Fune II}

"American Eclipse Expedition arrived at St. Francisco June I I. Holden reports no Vulcan as bright as $5^{\frac{1}{2}}$ magnitude. Hasting's observations prove the corona to be largely a phenomenon of diffraction by the great change in lengh of 1474 line on east and west sides of sun. No black lines in corona spectrum but D. Full observations with grating spectroscopes, prismatic telescope, and integrating spectroscope, by Rockwell, Upton, and Brown. Contacts by Preston. English and French parties successful.

$$
\text { (Signed) }
$$

E. S. HOLDEN"

It will be seen from the above that the spectroscopic attack was a very strong one, and although the telegram gives only the results of the work of Prof. Hastings, these are of unusual interest. I propose, therefore, to devote attention to them in the present notice. It will, however, be well to anticipate my remarks by a prefatory notice of the eclipse work on which it throws light. For this purpose I can scarcely do better than give the following extract from an article which appeared in the Times on Monday last :-

"It was only really in the eclipse of I869 that we began to know anything about the corona, and it was only in the eclipse of 1870 that we began to appreciate what a very difficult problem was presented to us by that phenomenon. The then Astronomer-Royal and Prof. Maedler, to cite some among the eminent authorities writing after the eclipse of I860, had come to the conclusion that the corona was mainly a non solar phenomenon. That part of it, however, was undoubtedly solar was admitted by all, for the reason that it was seen before and after totality. In the eclipse of 1870 the idea that part of it was really non-solar was enormously strengthened by a comparison of observations maảe by different astronomers. Its shape seemed to change as the moon swept over it, and this obviously, if it were true, implied some action of the moon's edge and reflection by something between the observer and the moon. In 1871 , when the Government of India and the British Association took steps to have the corona photographed at the same time that it was carefully observed by the naked eye, the strange fact was first clearly indicated that the corona seen by the eye was a perfectly different thing to that recorded on the photographic plates. The explanation given at the time was that the coronal light was much more actinic than ordinary solar light of the same visible intensity, so that in the eye and on the photographic plate two different images were built up by different qualities of light proceeding from different sources. Hence the view was distinctly enunciated that the corona seen during eclipses was a dual phenomenon, partly solar, partly non-solar in its origin, the true solar corona being filamentous with variously-curved streamers, the visible corona being non-filamentous and consisting mainly of radial lines and rifts, extending to different distances from the edge of the moon "

This slight sketch may now be expanded by the following details. Thus, for instance, in March, I870, Prof. Young, discussing the then current views of the corona, wrote :- "It is not impossible that the so-called corona may be complex, some portion of its radiance may perhaps originate in our own atmosphere, though I do not yet find myself able to agree with the conclusion of Dr. Gould and Mr. Lockyer in this respect, and am strongly disposed to believe that the whole phenomenon is purely solar."

With reference to the eclipse of 1870 I wrote :--"At the commencement and end of totality, when the moon unequally covered the sun, the photographs have recorded an excess of light on the corona on the side where the limbs occur nearest in contact. I am told that this effect in one of Lord Lindsay's photographs is very striking; it is certainly so in one of Mr. Brothers'. In the drawings we have a slightly different effect. At the commencement
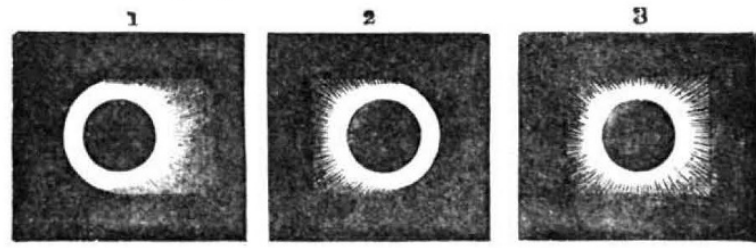

of totality, when the western or right-hand limbs were in contact, we get (see figure) I ; at the end of totality the appearance recorded was like 2 ; the picture at the middle of totality compounding both these appearances, and being roughly represented by 3 , in which the rectangular appearance comes out in its full strength."

Let us pass on to the eclipse of 187I. This was my description, written at the time, of what I saw :- "There, rigid in the heavens, was what struck everybody as a decoration, one that Emperors might fight for ; a thousand times more brilliant even than the star of India,- where we then were,- - a picture of surpassing loveliness, and giving one the idea of serenity among all the activity that was going on below, shining with a sheen as of silver essence, built up of rays almost symmetrically arranged round a bright ring above and below, with a marked absence of 
them right and 'eft, the rays being composed of sharp radial lines, separated by furrows of markedly less brilliancy."

After there had been time to examine the photographic records of the eclipse in connection with the above description, the enormous difference between the photograph and the eye picture was fully recognised, and in my lecture at the Royal Institution on the eclipse, after referring to the actinic corona, to the striking similarity in the details of the photographs taken at different times and in different places, I said : "The solar nature of most, if not all, of the corona recorded on the plates is established by the fact that the plates, taken in different places, and both at the beginning and end of totality, closely resemble each other, and much of the exterior detailed structure is a continuation of that observed in the inner portion independently determined by the spectroscope to belong to the sun."

Passing from the photographs to the drawings, I pointed out that in Mr. Holiday's sketch, for instance, we got an infinite number of dark radial lines extending down to the moon, with a greater extension than in the photographs, though in some places the shape of the actinic corona and some of its details were shown.

Thinking that this difference might be explained by different lights being superposed, so that of two superposed lights the naked eye used one, and the photographic plate the other, I asked the question whetber the facts might not be reconciled, and really harmonised with what was actually seen in the telescope, even by supposing that the visual image, this glare let us call it, was sifted in the telescope by using greater or less magnification in the same way as it was separated out on the photographic plates and in our eyes by the different qualities of the ligbt producing the visual and photographic images.

From this point of view, therefore, I regard Mr. Hasting's observation as one of very great interest, and I believe that it throws light upon a good many prior observations. I do not think, however, that any one will go with him when he proposes to abolish a true corona at the sun, for the reason that the observations to which $I$ have drawn attention show that it is really a dual phenomenon as I pointed out in 1870 , and although diffraction at the moon's edge may be the cause of one part, it cannot be the cause of the other. It is, perhaps, almost too early yet to speculate upon the changes in our views of the chemical nature of the external boundary of the sun's atmosphere which may be brought about by a complete discussion of the question which these observations again bring to the front. I long ago pointed out that the fact of getting in the spectroscope an indication of a line at so many minutes of arc from the limb of the dark moon, was by no means a proof of the existence of a vapour or gas at that height above the sun. Maclear's observation in 1870 was of course the test, for the reason that if such a caveat were not available we must assume the existence of coronal matter between us and the dark moon. But in any case it is not too early to bear this in mind, that if in our spectroscopes we have been dealing with a true glare, from whatever cause produced, there will be an almost complete inversion necessitated, and in this way: the brilliancy of any particular wave-length of the glare may either depend upon the area of the surface at the sun producing light of that wave-length, or upon its inherent intensity. Now if we assume that only the inherent intensity is to be considered, then obviously the region of greatest temperature will cause the brightest light. The brightest light will therefore be produced in the lowest level of the solar atmosphere, but because of the glare it will appear to extend to the greatest distance from the sun. It may therefore have been that the line 1474 , instead of indicating, as it has been supposed to do, that a substance which gives a line at the part of the solar atmosphere most removed from the photosphere is really produced by that part of the atmosphere, was produced at that part of the atmosphere nearest the photosphere, and really at first sight-although this is by no means a matter on which one would wish to commit one's self hastily-it does seem as if this view would harmonise a great many facts which are very difficult of explanation in any other way.

I discovered the line I474 in the chromosphere on June 6,1869 , and up to that time no bright line had been observed beyond those belonging to the spectra of hydrogen, sodium, and magnesium, with the exception of one line of barium, which was first seen in March, 1869. Now we know from the long-extended series of such observations for which we have to thank the industry of the Italian observers, that the line 1474 is now seen more persistently than any line which is not recorded in the spectra of hydrogen, magnesium, and sodium. The eclipse of last year taught us, if it taught us anything, that the lines which are thus persistent are the lines produced at the temperature of the hottest layers, and, if subsequent inquiry strengthens the view that the height to which the line I 474 appears to extend is really due to the depth at which the substance which produces it is restricted, the persistence of 1474 in ordinary chromospheric observations will be at once explained.

\section{J. NORMAN LOCKYER}

\section{AGRICULTURE IN $\mathcal{F A P A N}$}

D. LIEBSCHER'S little work is the result, the author tells us, of his investigations during an eight months' sojourn in Japan in 1880 . A cursory glance at the contents shows that it bears the physiognomy of a strictly scientific work. The work is divided into five parts :-(I) The condition of the climate and its influence upon the land-products ; (2) the condition of soils and its influence upon the land-products ; (3) the social condition before the year 1868 (before the reformation) ; (4) the reformation and reorganisation of the State since the year I 868 ; (5) foreign commerce. I shall notice shortly edch chapter with some remarks. Beginning with the first chapter, Dr. Liebscher commences with the monsoon, within whose sphere Japan is situated. It has, as is well known, a certain determined direction during the whole year. The summer (south-west) monsoon comes from the south-west from April to September, while the winter (north-east) monsoon comes from the northeast during the rest of the year. To the first, according to Dr. Liebscher, Japan owes its tropical flora, such as Chamarops excelsa, Thea viridis, Cycas revoluta, \&c., and to the same he attributes the chief land-products, such as cotton, sugar-cane, tobacco, Indian corn, and rice. Why the summer monsoon is so favourable to the growth of the land-products is because, says the author, it causes a warm temperature, and the abundant precipitation of rain (maximum $1794 \mathrm{~mm}$. in a year). He ignores then altogether the geographical position of Japan, that on one side she lies partly in a subtropical and temperate zone, on the other she is surrounded on all sides by a large body of water. The north-east monsoon brings a dry and terribly cold winter, though somewhat modified by the "Kuro-Siwo" current and this monsoon is the sole factor that renders the climate unfavourable, causing the remarkable phenomenon of the "freezing of the soil." Dr. Liebscher says, the regular course of the monsoon assures the people who happen to inhabit those lands which lie within the sphere of that wind, of a never-failing good crop of rice. Thus we are accustomed to depend solely upon rice, and

I "Japan's landwirthschaftliche und allgemeinwirthschaftliche Verhältnisse nach eigenen Beobachtungen dargestellt." Von Dr. G. Liebscher. (Jena r882.) 